\title{
Research on the Origin and Composition of Alliance Portfolio Management Ability
}

\author{
Junjie Yin \\ School of Management and Economics, Civil Aviation Flight University of China, Guanghan 618307, China \\ yinjunjieuestc@126.com
}

\begin{abstract}
With the increase in innovation risk and the acceleration of technological iterations, a single bilateral alliance cannot meet the needs of corporate innovation activities. More and more companies have established multiple alliance relationships with cross-regional and cross-industry external organizations at the same time. However, most companies are still unable to systematically manage alliance portfolios from a holistic perspective, and usually only focus on conflicts and competitive behaviors between alliances. If an enterprise wants to build a high-performance alliance portfolio, it must have the ability to develop and manage several external alliance relationships, that is, the ability to manage alliance portfolios. Based on the combing and analysis of related research results, the origin and connotation of alliance portfolio management capabilities are systematically analyzed, providing a new perspective for innovation management research in alliance portfolios.
\end{abstract}

Keywords: Open innovation, Organizational form, Alliance portfolio, Management ability.

\section{Introduction}

The rise of the open innovation paradigm has caused major changes in the traditional industrial organization. Corporate innovation activities require the crossover and integration of knowledge in different disciplines. The original bilateral alliances can no longer meet their technological innovation needs. More and more Enterprises simultaneously form several alliances in cross-industry and cross-geographical areas. Enterprises and external organizations have established multiple alliances at the same time, and the resulting set of alliance organizations with the enterprise itself as the core is called alliance portfolio (Lavie, 2007; Wassmer, 2010).

It is not uncommon for a large number of companies to establish multiple alliances to gain a competitive advantage. For example, from the perspective of the US software industry, in the early 1990s, less than one-third of listed companies had established external alliances. Ten years later, this proportion was close to $100 \%$, and the average external alliance of each company. The number has also jumped from 4 to more than 50 (Lavie, 2007). The evolution from a bilateral alliance in the original sense to an alliance portfolio of network organizations is an inevitable choice for enterprises to successfully achieve technological innovation.

Although the alliance portfolio has shown strong utility in enhancing the innovation advantages of enterprises, research has found that the failure rate of alliances in practice remains high. Statistics show that more than half of the strategic alliances have failed to succeed (Heimeriks, Klijn, \& Reuer, 2009). These studies show that there is a high risk of failure in the alliance, and the reasons for failure are many. For example, when forming an alliance portfolio, the focus enterprise seldom considers the degree of matching between itself and the alliance partner, and it is difficult to obtain the required capabilities and knowledge from the alliance partner; secondly, the focus enterprise lacks the overall planning and design of the alliance portfolio, and it is difficult to grasp the alliance The timing of formation and termination, and it is impossible to formulate effective deterrent measures against opportunistic behaviors that damage the interests of other alliance members; third, the resources in the alliance portfolio can only be transferred efficiently and smoothly under certain organizational arrangements or coordination mechanisms. And the lack of effective coordination and communication between the various subjects, the focus of the enterprise can not build an atmosphere of learning and communication, resulting in the related partner resources can not be transformed into the common knowledge and capabilities in the alliance portfolio. Finally, the alliance portfolio shows more complex relationships in terms of network scale, network structure, and network relationships. It is difficult for focus companies to fully control the evolution of the alliance portfolio, the organizational cultural background, organizational practices, and differences among alliance members. Factors such as strategic objectives have led to increased difficulty in alliance portfolio management. The instability and high failure rate of alliances in reality fully illustrate this problem. Therefore, a problem that focal companies often face is how to manage multiple alliances, that is, how to achieve effective management of alliance portfolios.

Based on this, this article analyzes the connotation of alliance portfolio management capabilities through reference and integration of previous research results from the perspective of resource-based view, and then provides a theoretical basis for enterprises to efficiently use resources in the alliance portfolio to win and maintain competitive advantages. It also provides practical guidance for companies to effectively establish and manage alliance portfolios and improve cooperative innovation performance.

\section{Literature Review}

\subsection{The Emergence of Alliances}

The alliance portfolio is a dynamic alliance relationship network centered on the focus enterprise, and it is a dynamic collection of the strategic alliance of the focus enterprise. At present, technology and market are the two main motivations for enterprises to make alliances (Reuer \& Ragozzino, 2006; Goerzen, 2007; Ozcan \& Eisenhardt, 2009). Technical 
motives are mainly to obtain invisible knowledge, identify innovation opportunities, reduce innovation costs, and shorten the research and development cycle, while the market motives are mainly to obtain additional market shares, further enrich the existing market structure and new markets. Expansion, etc. These two motives can explain to a certain extent the reasons for the formation of the alliance portfolio, but the alliance portfolio is not simply the sum of several alliances, but is the result of parallel alliance interactions driven by diversified goals and different motivations.

As an important organizational form to achieve strategic goals, alliance portfolio provides companies with access to external resources and capabilities, but novel and valuable non-redundant knowledge or information may not be fully shared within the alliance portfolio (Cui \& O 'Connor, 2012). At the same time, the alliance portfolio is composed of alliance partners with related interests. Each alliance is often self-interested and it is difficult to take into account the interests of other members. It may fall into a certain disorder or "prisoner's dilemma", and the overall advantage of the alliance portfolio is difficult to maximize (Faems, Janssens, \& Neyens, 2012; Veiga \& Franco, 2015). For focus enterprises, alliance portfolio means larger alliance scale, more complex alliance structure and alliance relationship, and enterprises need to coordinate and manage the flow of information and resources between alliances (Hoffmann, 2007; Haider \& Mariotti, 2016). As the size of the alliance portfolio expands and the heterogeneity of its members increases, the focus enterprise will have additional management tasks in the process of its organization and coordination (Parise \& Casher, 2003; Hoffmann, 2007). However, most companies are still unable to systematically manage alliance portfolios from an overall perspective. They usually only focus on conflicts and competitive behaviors between alliances. Only a few companies will consider the complementary and coordinated relationship between these alliances (Kale \& Singh, 2009). As a result, researchers realized that the management of the alliance portfolio is no longer just about the management of the alliance partners and the alliance itself, but needs to be based on the overall network of the alliance partners, and minimize the relationship between the various alliances from the perspective of the overall situation and the combination. Friction, give full play to the synergy in the alliance portfolio (Parise \& Casher, 2003).

\subsection{Proposal of Alliance Portfolio Management Ability}

As the complexity and scale of the alliance portfolio increase, coordinating and organizing the alliance portfolio of the enterprise will cause additional management tasks for the enterprise. Enterprises are embedded in a network of competitors, customers, suppliers, technology providers, capital providers, consulting companies, etc. These alliances will affect the competitive advantage of enterprises to a large extent (Lichtenthaler, 2016).

Focus enterprises must not only consider whether to establish and maintain alliance relationships with external partners, but also learn to effectively manage these relationships, and effectively integrate partner resources and capabilities with their own resources and capabilities at the combined level to create the greatest alliance value. Existing documents have explored the positive effects of alliance portfolio management on corporate technological innovation activities. For example, Gonçalves \& Conceição (2008) used the survey data of pharmaceutical companies to find that alliance portfolio management capabilities have a significant effect on the relationship between alliance portfolio and corporate financial performance. Positive moderating effect; Faems, Janssens, \& Neyens (2012) concluded that the alliance portfolio management mechanism strengthens the positive impact of partner heterogeneity on corporate innovation performance; Sarkar, Aulakh, \& Madhok (2009) The empirical results of point out that alliance portfolio management capabilities will improve the market performance of enterprises through the intermediary effect of alliance portfolio capital. Alliance portfolio management capabilities are the key to maximizing the utility of alliance portfolios and ensuring the technological innovation activities of focus enterprises. The higher the alliance portfolio management ability, the more the enterprise can use the network resources contained in the alliance portfolio to create innovative income. After an enterprise has formed and applied this capability, the faster the development of new products, the more likely it is to produce technological breakthrough products. The higher the success rate of commercial $\mathrm{R} \& \mathrm{D}$, the faster the speed of entering new markets. It can be seen that the performance difference of the focus enterprise in the alliance portfolio reflects the heterogeneity of the enterprise's alliance portfolio management ability, or the different path of the enterprise in the development and implementation of the alliance strategy. In other words, efficient cooperation performance and competitive advantage are determined by how the enterprise manages and operates the alliance portfolio.

\section{Analysis of the Connotation of Alliance Portfolio Management Capabilities}

\subsection{The Origin of Alliance Portfolio Management Capabilities}

The management of alliance portfolio is a complex and dynamic process. The experience of a single alliance management is the basis for the management of the alliance portfolio of the focus enterprise. However, due to the dependence and complementarity of multiple alliance entities in the combination, the management of the alliance portfolio is not a simple cumulative process. First of all, the emergence and evolution of the alliance portfolio is different from a single alliance, it involves the construction, governance, coordination and strategic configuration of the entire alliance portfolio. In a single alliance, the enterprise's demand for resources plays a key role, and the enterprise usually directly selects those enterprises that have the resources they need to form an alliance with it. In the process of forming the alliance portfolio, the company will comprehensively examine the differences in resources, capabilities, knowledge and technical foundations between alliance partners to avoid resource redundancy and duplicate investment. Secondly, the alliance portfolio is the "self-centered network" of the focus enterprise and the core alliance network that the focus enterprise can control. Therefore, more emphasis is placed on the planning and regulation of all alliances. The network structure of the alliance portfolio will be affected by the behavior of the enterprise alliance, and the change of the 
network structure will directly affect the power and status of the focus enterprise in the alliance portfolio. Finally, the management of the alliance portfolio requires the senior management of the enterprise to have a more macroscopic view of the overall situation, keep an eye on the changes in the external environment, and dynamically adjust the strategic deployment of the alliance portfolio to establish a more systematic and professional management process and Convention.

Wassmer believes that the alliance portfolio management capability is a high-level capability based on the enterprise alliance capability, including determining its strategic development mode, establishing an alliance management system, and coordinating and supervising the operation of the alliance. Heimeriks et al. proposed four basic categories of alliance management tasks from the perspective of capabilities, including functions and staffing, management tool training, and third-party management. Schreiner et al. emphasized the need to carefully select alliance partners to ensure that the selected alliance partners can coexist harmoniously with existing alliance partners. Faem et al. described the three dimensions of alliance portfolio management from the perspective of organizational design: centralization, formalization, and customization, and pointed out that alliance portfolio management needs to be consistent with its structure (such as: scale, heterogeneity, etc.) Matching can realize the synergy effect within the combination. Gonçalves and Goncalves regard alliance portfolio management as a process of integrating resources and forming organizational routines. Its purpose is to perceive external crises and explore new opportunities, and at the same time promote the effective transfer of resources within the portfolio and the formation of synergies.

\subsection{Dimensional Analysis of the Alliance Portfolio Construct}

Based on the existing theoretical research, this research is based on the perspective of the enterprise, and believes that the alliance portfolio management capability is the ability of the enterprise to obtain a competitive advantage by identifying the value and opportunity of the alliance, designing and shaping the alliance portfolio, and using, maintaining and coordinating the alliance relationship at all levels. ability. Based on the perspective of the process view, combined with the existing research on the dimension division of alliance portfolio management capabilities, this study appropriately integrates and expands its dimensions, and finally divides them into the following dimensions: (1) Forward-looking planning capabilities reflect the company's external Perception of the environment and internal design adjustments; (2) Portfolio construction capabilities, which reflect the company's ability to proactively identify, evaluate, and establish external alliance relationships; (3) Relationship optimization capabilities, which reflect the company's use of flexible methods to solve and resolve Conflict ability; (4) Combination coordination ability, which reflects the enterprise's ability to flexibly configure and coordinate the relationship, resources, skills and innovative activities among the members of the alliance portfolio.

\subsubsection{Forward-looking planning ability}

Forward-looking planning ability refers to the ability of a focus enterprise to plan and deploy alliance relationships based on future development visions and make dynamic adjustments based on internal and external environments through perception and prediction of the overall situation and environment of the alliance portfolio in accordance with its own strategic needs. The forward-looking planning ability reflects the focus of the enterprise's awareness and understanding of the external environment and alliance relationships, and helps the enterprise identify and evaluate the knowledge resources of alliance partners, initiate alliance relationships and adjust the portfolio structure from a strategic height. For example, in the case of fierce competition in the external market and scarce resources, whether the focus enterprise should expand or reduce the size of the alliance portfolio depends on forward-looking planning capabilities.

The planning and formation of the alliance portfolio is the embodiment of the strategic decision of the focus enterprise. The quality of the strategic planning highlights the perception ability of the focus enterprise, and the configuration characteristics of the alliance portfolio show the level of perception and the quality of construction. Only when the focus enterprise conducts strategic planning of alliance portfolio based on the external environment and its own cognition and insight, can it be possible to obtain competitive advantage and higher performance from it (Ozcan \& Eisenhardt, 2009). Focus companies with strong forward-looking planning capabilities are also better able to grasp the direction of industry development and grasp the distribution of key resources, which can better integrate alliance portfolio with industrial reality, clarify potential alliance partners, and outline alliances with heterogeneous resources Relationship layout. At the same time, the perception of the external environment helps focus companies to discover and occupy structural holes in the partnership, which has a significant impact on the company's market expansion and improvement of innovation capabilities (Zaheer \& Bell). Therefore, focus companies need to actively pay attention to and participate in alliance strategic activities, obtain relevant key information through planning internal and external connections, and be able to grasp relevant information about industry technology development and market changes, systematically evaluate this information, and accurately predict alliances Combine the evolution direction, adjust the development strategy in time, reduce the lock-in effect and achieve the best benefits.

\subsubsection{Combination construction ability}

Combination building ability is the ability of the focus enterprise to actively identify and evaluate suitable potential alliance partners from a strategic point of view, and to establish effective alliance relationships so that the enterprise can occupy an advantageous position in the alliance portfolio. Combination building ability belongs to the operational ability at the network level, which is mainly manifested in actively searching for the best alliance partners, building effective alliance relationships, expanding the size of the alliance portfolio, adjusting its position in the alliance portfolio, etc. The size of the combination building ability can reflect in terms of the size of the alliance portfolio, the 
diversity of alliance functions, and the diversity of alliance partners.

After enterprises have planned and deployed their alliance portfolio at the strategic level, they are faced with the problems of identifying suitable alliance partners, building complementary alliances, and embedding themselves in the advantageous position of the alliance portfolio (Andrevski, Brass, \& Ferrier, 2016). Combination building capabilities require companies to clarify the external resources and capabilities they need for their own development, and then to screen whether potential alliance partners meet current and future needs, such as expanding new business markets and formulating industry standards. The size of the combination building ability determines the quantity and quality of resources and capabilities that an enterprise can obtain from the alliance portfolio, as well as the efficiency of resource flow in the combination, and it is also a guarantee for the enterprise to occupy a dominant structural position in the alliance portfolio. A suitable alliance partner means that the alliance portfolio will have greater potential benefits (Lin, Yang \& Arya, 2009), which requires companies to actively search, identify and attract Enterprises that fit in with themselves build alliance portfolios. Appropriate alliance partners can increase access to corporate resources and benefits, promote the exchange of resources between companies, and bring about an improvement in innovation performance.

\subsubsection{Relationship optimization ability}

Focus companies need to attract and screen alliance partners, and on the other hand, they need to know how to properly maintain mutual relationships. The ability of an enterprise to optimize relationships is embodied in relationship coordination and maintenance. For the focus enterprise, it is necessary to handle the relationship with the enterprises within the alliance portfolio. However, the alliance portfolio covers different types of relationships. At the same time, it is also full of conflicts caused by the differences in the alliance partners' own different cultures and operating concepts (Duysters, Heimeriks, \& Lokshin, 2012). Therefore, the relationship between a large number of heterogeneous organizations in the alliance portfolio means the complexity of management and the corresponding increase in management costs, and whether these alliance relationships are coordinated directly affects the operational efficiency of the alliance portfolio (Wassmer, 2010; Heimeriks, Klijn, \& Reuer 2009).

The ability of relationship optimization refers to the ability of enterprises to use informal rules to realize the flexible management of alliance portfolio, so as to avoid opportunistic behavior of alliance partners and realize the coordinated development of relationships among alliance partners. Relationship optimization ability plays a very important role in the process of alliance establishment and termination. Specifically, at the beginning of the alliance construction stage, the ability to optimize relationships means whether the focus enterprise can quickly, economically, and efficiently form a mutually recognized cooperative relationship with the alliance partners. During the development period of the alliance relationship, the ability of relationship optimization determines whether the focus enterprise can realize the potential value of alliance partners to the greatest extent on the basis of avoiding alliance conflicts. When the alliance relationship is terminated, whether the focus enterprise can flexibly terminate the alliance relationship is a manifestation of its relationship optimization ability level. Focus enterprises can realize formal and informal communication and exchanges between partners within the alliance through the use of relationship optimization capabilities, and flexibly alleviate, coordinate and manage conflicts and contradictions caused by a series of differences within the alliance portfolio.

\subsubsection{Combination and coordination ability}

Combination coordination ability is the ability of the focus enterprise to flexibly configure and integrate the strategies, behaviors and knowledge among different partners in the alliance portfolio. Alliance portfolio provides companies with access to external resources and capabilities, but new and valuable non-redundant knowledge or information may not be fully shared within the alliance portfolio. This requires the focus of the enterprise to understand the resources and capabilities in the alliance portfolio. The ability to effectively coordinate and integrate to promote the use of existing resources and the reorganization of new resources to maximize the synergy effect (Kale \& Singh, 2009; Golonka \& Latusek, 2016). The coordination and integration here include two aspects. One is the coordination and integration of a single alliance to achieve the maximum effect of resources and capabilities within a single alliance, and the other is the coordination and integration between the alliance and the alliance, that is, the focus enterprise is based on The strategic level promotes the matching of strategic actions and resource capabilities within the portfolio, thereby optimizing the overall value and benefits of the alliance portfolio.

Focus enterprises can improve the operational efficiency of the alliance portfolio through combination and coordination capabilities, which is manifested in clarifying the resources and capabilities of alliance partners, discovering the associations between differentiated knowledge and information modules, and being able to configure and integrate these resources in the most efficient way And ability to make full use of high-quality resources and capabilities to promote the effective use of existing resources and the development of new resources, so that the resources and capabilities of each subject can be combined organically, that is, all subjects of the alliance portfolio can share and be effective Utilization will eventually make it the foundation of the enterprise's technological innovation capability and competitive advantage. Therefore, the combination and coordination ability of the enterprise is very important. It is an "accelerator" to improve the operation efficiency of the alliance portfolio. It can make the node links of the alliance portfolio operate normally, so that the disordered resources and capabilities can be ordered, and through the matching of alliance partners. In order to supplement and enhance each other, enhance the synergy effect within the alliance portfolio.

\section{Research Conclusion}

Regarding the connotation and dimensions of alliance portfolio management capabilities, scholars have not formed a 
complete and consistent view. In the existing research on alliance portfolio management capabilities, alliance experience, knowledge management, relationship governance, and communication and coordination are usually regarded as alliance portfolio management. The external performance of ability (Kale \& Singh, 2007; Hoffmann, 2005, 2007). This article integrates the theoretical results of resource theory, organizational learning theory and innovation management, and closely combines the practice of enterprise technology innovation and alliance management, systematically analyzes the origin and connotation of alliance portfolio management capabilities, and provides new ideas for innovation management research in alliance portfolios. The angle of view has enriched the theoretical system of alliance portfolio, and made some exploratory attempts to further study the role and essential meaning of alliance portfolio management capabilities.

From a practical point of view, in the current increasingly competitive external environment, building alliances to obtain complementary resources and enhance innovation capabilities has become the key to enterprises gaining and maintaining long-term competitive advantages. Most companies tend to place too much emphasis on external conditions such as the number of alliances and partner quality in the establishment and operation of alliance portfolios, but they have neglected how to effectively coordinate and manage these alliances to produce an overall combination effect, and rigidly disperse their energy and resources to each individual. Each alliance is managed separately. To change this situation, it is necessary to cultivate the enterprise's alliance portfolio management ability, so as to maximize the potential advantages of the alliance portfolio and effectively realize the diversified development of technological innovation. Based on the consideration of this realistic situation, this research deeply explores the connotation of enterprise alliance portfolio capabilities, guides enterprise alliance management thinking from bilateral to portfolio level, deeply understands the internal operation mechanism of alliance portfolio, and guides enterprises to effectively establish, manage alliance portfolio and improve The performance of cooperative innovation has important practical significance.

\section{References}

[1] D. Lavie. Alliance portfolios and firm performance: A study of value creation and appropriation in the us software industry[J]. Strategic Management Journal, 2007, 28(12): 1187-1212.

[2] U. Wassmer. Alliance portfolios: A review and research agenda[J]. Journal of Management. 2010, 36 (1):141-171.

[3] K. H. Heimeriks, E. Klijn, J. J. Reuer. Building capabilities for alliance portfolios[J]. Long Range Planning, 2009, 42(1): 96-114.

[4] J. J. Reuer, R. Ragozzino. Agency hazards and alliance portfolios[J]. Strategic Management Journal, 2006, 27(1):27-43

[5] P. Ozcan, K. M. Eisenhardt. Origin of alliance portfolios: Entrepreneurers network strategies, and firm performance[J]. Academy of Management Journal. 2009, 52(2): 246-279.
[6] A. Goerzen. Alliance networks and firm performance: The impact of repeated partnerships[J]. Strategic Management Journal, 2007, 28(5): 487-509.

[7] A. S. Cui, G. O’Connor. Alliance portfolio resource diversity and firm innovation $[\mathrm{J}]$. Social Science Electronic Publishing, 2012, 32(4): 83-93.

[8] D. Faems, M. Janssens, I. Neyens. Alliance portfolios and innovation performance: Connecting structural and managerial perspectives[J]. Group \& Organization Management: An International Journal. 2012, 37(2): 241-268.

[9] P. M. Veiga, M. Franco. Alliance portfolios and firms' business strategy: A content analysis approach[J]. Management Research Review, 2015, 38(11): 1149-1171.

[10] W. H. Hoffmann. Strategies for managing a portfolio of alliances[J]. Strategic Management Journal, 2007, 28(8): 827-856.

[11] S. Haider, F. Mariotti. The orchestration of alliance portfolios: The role of alliance portfolio capability $[\mathrm{J}]$. Scandinavian Journal of Management, 2016, 32(3): 127-141.

[12] S. Parise, A. Casher. Alliance portfolios: Designing and managing your network of business-partner relationships[J]. The Academy of Management Executive, 2003, 17(4): 25-39.

[13] P. Kale, H. Singh. Managing strategic alliances: What do we know now, and where do we go from here?[J]. The Academy of Management Perspectives, 2009: 45-62.

[14] F. R. Gonçalves, V. G. da Conceição. Strategic alliances and competitive performance in the pharmaceutical industry[J]. Journal of Medical Marketing, 2008, 8(1): 69-76.

[15] M. B. Sarkar, P. S. Aulakh, A. Madhok. Process capabilities and value generation in alliance portfolios[J]. Organization Science, 2009, 20(3): 583-600.

[16] K. H. Heimeriks, G. Duysters. Alliance capability as a mediator between experience and alliance performance: An empirical investigation into the alliance capability development process[J]. Journal of Management Studies, 2007, 44(1): 25-49.

[17] E. V. Hippe. "Sticky information" and the locus of problem solving: Implications for innovation[J]. Management Science, 1994, 40(4): 429-439.

[18] F. Selnes, J. Sallis. Promoting relationship learning[J]. Journal of Marketing, 2003, 67(3): 80-95.

[19] Zaheer, G. G. Bell. Benefiting from network position: firm capabilities, structural holes, and performance $[\mathrm{J}]$. Strategic Management Journal, 2005, 26(9): 809-825.

[20] G. Andrevski, D. J. Brass, W. J. Ferrier. Alliance portfolio configurations and competitive action frequency[J]. Journal of Management, 2016, 42(4): 811-837.

[21] Z. Lin, H. Yang, B. Arya. Alliance partners and firm performance: resource complementarity and status association[J]. Strategic Management Journal, 2009, 30(9): 921-940.

[22] G. Duysters, K. H. Heimeriks, B. Lokshin. Do firms learn to manage alliance portfolio diversity? The diversity-performance relationship and the moderating effects of experience and capability[J]. European Management Review, 2012, 9(3): 139-152. 
[23] M. Golonka, D. Latusek. Alliance portfolio formation and configuration by small and medium ICT firms $[\mathrm{J}]$. Baltic Journal of Management, 2016, 11(1): 65-88.

\section{Author Profile}

Junjie Yin received Ph.D. in management from the University of Electronic Science and Technology of China in 2018. And he is currently mainly engaged in the research of technological innovation management. 